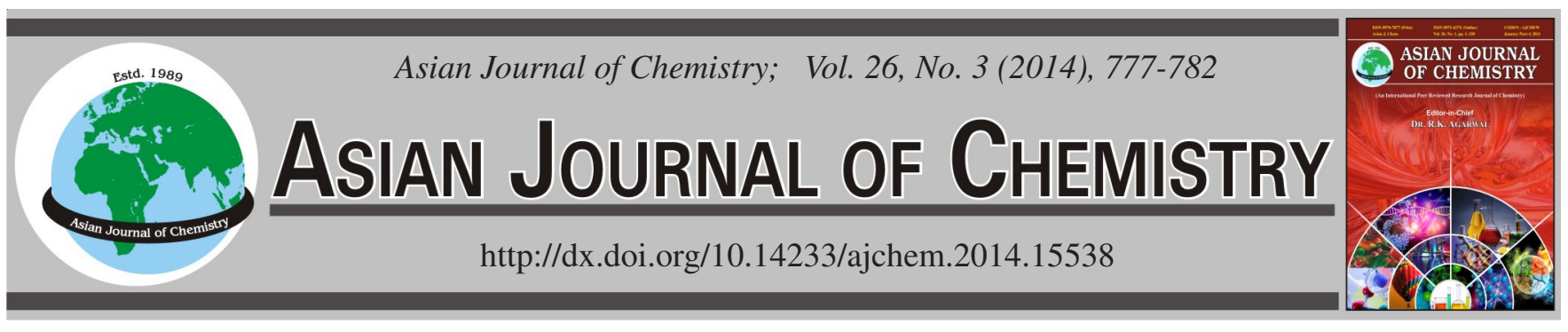

\title{
Identification and Quantification of Volatile and Phenolic Compounds Composition in Buckwheat Sprouts by GC/MS and HPLC
}

\author{
Sun-Ju Kim ${ }^{1}$, Md. Musfiqur Rahman ${ }^{2}$, Min-Kee Lee ${ }^{1}$, Jeong Min Seo ${ }^{1}$, Mariadhas Valan Arasu ${ }^{1}$, \\ Tatsuro Suzuki ${ }^{3}$, N.A. Al-Dhabi ${ }^{4}$, Young-Ho Yoon ${ }^{4, *}$ and Jae-Han Shim ${ }^{2, *}$
}

\begin{abstract}
${ }^{1}$ Department of Bio-Environmental Chemistry, Chungnam National University, Daehak-Ro 99, Yusung-Gu, Daejon 305-764, Republic of Korea ${ }^{2}$ Natural Products Chemistry Laboratory, Institute of Agricultural Science and Technology, College of Agriculture and Life Science, Chonnam National University, 300 Yong-Bong Dong, Buk-Ku, Gwangju 500-757, Republic of Korea

${ }^{3}$ National Agricultural Research Center for Hokkaido Region, Shinsei, Memuro, 8 Kasai-Gun, Hokkaido 082-0081, Japan

${ }^{4}$ Department of Botany and Microbiology, Addiriyah Chair for Environmental Studies, College of Science, King Saud University, Riyadh 11451, Saudi Arabia

${ }^{5}$ Highland Agriculture Research Center, National Institute of Crop Science, Rural Development Administration, Pyeongchang 232-955, Republic of Korea
\end{abstract}

*Corresponding authors: Tel: +82 33330 1513,+82 62530 2135; E-mail: yhyoon@korea.kr; jhshim@ chonnam.ac.kr

The objective of this study was to determine the contents of volatile and phenolic compounds from 10 varieties of buckwheat sprouts. GC/MS analysis guided to identify amines and their derivatives (5), alcohol and derivatives (7), aldehydes (3), acids (4), ketone and derivatives (5), ester and derivatives (7). Alcohols and ester derivatives shared highest contents among all of the volatile compounds determined (20\%). Phenolic compounds, including chlorogenic acid, four C-glycosylflavones (orientin, isoorientin vitexin, isovitexin), rutin and quercetin, were determined in the seed sprouts. The contents of total phenolic compounds ranged from 32.86 to $50.0 \mathrm{mg} / \mathrm{g}$ dry weight. Based on these results, the presence of different groups of volatile and phenolic compounds in all the varieties of buckwheat vegetables conformed that it can be regarded as a potent source of functional food.

Keywords: Buckwheat, GC/MS, Volatile compounds, Phenolic compounds, Rutin.

\section{INTRODUCTION}

Buckwheat (Fagopyrum esculentum Moench) is a broad leafed herbaceous belongs to the family Polygonaceae, which is generally referred as the rhubarb or sorrel family. However, because its seeds are structurally and chemically resembles as cereal grains, buckwheat is classed with the cereal groups. It is originated in the mountain regions of southern China and produced in many parts of the world and has long been an important part of the human diet ${ }^{1}$. The products developed from buckwheat have attained an excellent reputation for its nutritious qualities in the human diet. Its renewed popularity with many bioactive components, which have been shown to provide various health benefits after natural foods. Because if its carbohydrates, proteins (10-15\%), amino acids and minerals ${ }^{2}$. It has 9 varieties of fatty acid are mostly unsaturated oleic acid and linoleic acid. The content of vitamin $\mathrm{B}_{1}, \mathrm{~B}_{2}$, is also higher than that in other principal cereal crops. Additionally it contained chlorophyll and bio-flavonoids, which are absent in other cereals, are quite helpful to human body's digestion of food and absorption of nutrients. Tartary buckwheat flour is known for plenty of nutritive mineral elements (Fe, $\mathrm{Ca}, \mathrm{P}$, $\mathrm{Cu}, \mathrm{Zn}$ and $\mathrm{Mg}$ ) and microelements (B, I, CO and Se) $)^{3}$. Buckwheat is known for high contents of phenolic compounds ${ }^{4}$. Among the different flavonoid, rutin is identified as the main phenolic constituent, whereas vitexin and chlorogenic acid occur in substantial amounts 5 . These phenolic compounds are known for its antioxidant activities ${ }^{6,7}$. Therefore, buckwheat is considered as potential to serve as a functional food ${ }^{8}$. It has also been reported that buckwheat has many nutritional and medicinal functions. It has been used in China as a traditional medicine to invigorate the stomach and promote urination. In some cases, this buckwheat can be used in the treatment of diabetes and cardiovascular diseases which is attributed to its phenolic contents like rutin and quercetin ${ }^{9}$.

In recent years, interestingly more products derived from buckwheat have entered into the daily lives of humans in the form of dried seeds, sprouts and nutrition powders. In addition to its nutritional benefits, the unique flavor of the buckwheat seeds and sprouts are one of the main reasons why consumers 
prefer it. Odour is considered as a critical quality trait in cereals; it attracts consumer preference because it travels to the nose during consumption and stimulates the olfactory receptors in the nasal cavity ${ }^{10}$. Freshly harvested and milled buckwheat stimulates appetizing in human. Volatile constituents of the grains are believed to play a major role in its flavour, but there is little information about odour activity of these components in buckwheat. The aromatic characteristics of various cereals, such as rice, corn, wheat and buckwheat have been studied in its different prospective of the volatile compounds ${ }^{11-13}$. Aldehydes, alcohols, ketones, benzene derivatives, hydrocarbons, acids, esters and sulphur-containing compounds are the main volatile compounds present in cereals. Among the different volatile compounds in buckwheat, salicyl aldehyde was identified as major aroma compound besides that nonanal ${ }^{13}$, octanal and hexanal detected in smaller quantities ${ }^{1}$. Dehusking and polishing steps in grain processing not only improve the sensory and edible quality of grain but also yield the main product and by-products. In the previous report, we have studied the levels of phenolic and anthocyanin contents and the correlation between antioxidant activitiesv ${ }^{14-16}$. However, most of these studies have focused on levels of bioactive nutrient compositions but have ignored differences in the volatile compounds. There are two cultivating species such as common (Fagopyrum esculentum Moench).) and Tartary buckwheats (F. tataricum Gaertn.). Therefore, the main objective of this research was to identify and compare the volatile components of ten varieties of buckwheat sprouts using gas chromatography-mass spectrometry (GC/MS) and quantify its phenolic contents by High performance liquid chromatography (HPLC).

\section{EXPERIMENTAL}

HPLC grade acetonitrile $\left(\mathrm{CH}_{3} \mathrm{CN}\right)$ and methanol $(\mathrm{MeOH})$ were purchased from Wako Pure Chemical Industries (Osaka,
Japan). Authentic compounds such as chlorogenic acid and flavonoids involving C-glycosylflavones (orientin, isoorientin vitexin and isovitexin), rutin and quercetin were supplied by Extrasynthese (Genay, France) for external standards.

Plant materials and cultivation: Ten cultivars such as 'Dawon', 'Sewon', 'Yangjeol', 'Daekwan 3-3' were provided from Rural Development Administration (RDA), Korea and 'Kitawase', 'Hokkai T 9' and 'Hokkai T 10' were provided Hokkaido Agricultural Research Center (HARC), Japan. Commercial Asia, unknown its variety name, were purchased from Asia seed Co. Ltd. (Seoul, Korea) and Hwang-Hokkai T 10 ' cultivated in 2011 in the green house of Chonnam National University. Among them 'Hokkai T 9' and 'Hokkai T 10', Hwang-Hokkai T 10' and 'Daekwan 3-3' were Tartary buckwheat (Fagopyrum tataricum Gaertn.) and the others were common buckwheat (F. esculentum Moench). Buckwheat seeds $(10 \mathrm{~g})$ previously sterilized with $10 \%$ (v/v) sodium hypochlorite $(\mathrm{NaClO})$ for $3 \mathrm{~h}$ were sown in plastic pots $(6.5$ $\mathrm{cm} \times 6.5 \mathrm{~cm} \times 15 \mathrm{~cm})$. After germination in a growth chamber at $25^{\circ} \mathrm{C}$ for 14 days in the dark, the buckwheat sprouts were harvested and immediately measured and weighed their height and fresh weight $(\mathrm{FW})$. After freeze drying, seed sprouts were weighted their dry weight (DW), ground with mortar and pestle and individually stored in desiccator until chemical analysis.

Solvent-free solid injector (SFSI) extraction procedure: A solvent-free solid injector device manufactured by Han Jin Precision Co. (Gwangju, Republic of Korea) was used for the injection of plant materials to the gas chromatograph equipped with Mass spectrometer (Fig. 1). A 1-mg weight representative sample of buckwheat sprout leaves was placed into a soft glass capillary tube (1.2 $\mathrm{mm}$ i.d. $\times 30 \mathrm{~mm}$ in length); both the ends of the tube were sealed briefly in a gas flame and the tube was then placed in a solvent-free solid injector (SFSI). The tube was crushed by lowering the injector plunger to carry the



Fig. 1. Drawing of Keele injector modified and used in this study. (Morgan, 1990) 
sample analytes onto the GC column by a career gas in a normal manner. The solvent free solid injector (SFSI) was held at the injection port during the pre-heating phase until the injector plunger reached the top of the injector septum, which allowed a constant pressure of carrier gas to be maintained during the analysis. The optimal conditions for SFSI were attained by sequentially varying one experimental parameter while all of the other parameters kept fixed. The parameters varied in an order of the injector temperature $\left(200,250\right.$ and $\left.300{ }^{\circ} \mathrm{C}\right)$, preheating time $(3,5,7$ and $10 \mathrm{~min})$ and holding time $(0,3,5,7$ and $10 \mathrm{~min}$ ). Finally injector temperature was fixed at $250{ }^{\circ} \mathrm{C}$; both pre-heating and holding time were optimized as $7 \mathrm{~min}$.

GC-MS analysis: An Agilent network GC system of model 6890 equipped with a 5973N mass-selective detector (Agilent Technologies, USA) was used to identify the volatile compounds emitted from the leaves of buckwheat sprouts. The separation of the compounds was carried out on an HP-5MS fused silica column $(30 \mathrm{~m} \times 0.25 \mathrm{~mm} \times 0.25 \mu \mathrm{m})$. The injector temperature was set at $250{ }^{\circ} \mathrm{C}$. The oven temperature was held at $50{ }^{\circ} \mathrm{C}$ for $4 \mathrm{~min}$ and gradually increased to $250{ }^{\circ} \mathrm{C}$ at a rate of $4{ }^{\circ} \mathrm{C} / \mathrm{min}$ and was held constant for $1 \mathrm{~min}$. High purity helium $(99.9999 \%)$ at a constant flow rate of $1 \mathrm{~mL} / \mathrm{min}$ was used as the carrier gas and the injection was made using split mode of 10:1. An electron impact mass spectral (EI-MS) analysis was carried out at ionization energy of $70 \mathrm{eV}$ at $250{ }^{\circ} \mathrm{C}$. The detection was performed in the scan mode between 10 and $400 \mathrm{amu}$ at $3.71 \mathrm{scans} / \mathrm{s}$.

Extraction and analysis of phenolic compounds: A 10 $\mathrm{mg}$ portion of the lyophilized powder was transferred into $1 \mathrm{~mL}$ $\mathrm{MeOH}$ containing $10 \%$ phosphoric acid $[0.1 \%(\mathrm{v} / \mathrm{v})]$ in a 2-mL Eppendorf tube. The solution was vigorously vortexed for $5 \mathrm{~min}$ and incubated at $37^{\circ} \mathrm{C}$ for $3 \mathrm{~h}$ and then centrifuged at $10,000 \mathrm{~g}$ for $5 \mathrm{~min}$. The extract was filtered through a $0.45 \mu \mathrm{m}$ PTFE syringe filter (Advantec DISMIC-13HP, Toyo Roshi Kaisha, Ltd., Tokyo, Japan). The filtrate was then analyzed by Perkin Elmer Flexar (USA) equipped with variable wavelength detector. The data were recorded with a Compaq Presario CQ3100KL computer (Samsung, South Korea) and analyzed by Chromera software.

The chromatographic separation was performed on Capcell PAK C18 column $(4.6 \times 250 \mathrm{~mm}, 5 \mu \mathrm{m}$; purchased from Shiseido, Tokyo, Japan. Detection was made at a wavelength of $350 \mathrm{~nm}$ and the column oven temperature was set at $40{ }^{\circ} \mathrm{C}$. The injection sling was $10 \mu \mathrm{L}$. The solvent system was delivered at a rate of $1 \mathrm{~mL} / \mathrm{min}$ and consisted of a mixture of (A) methanol/water/acetic acid (5:92.5:2.5, v/v/v) and (B) methanol/water/acetic acid acid $(95: 2.5: 2.5, \mathrm{v} / \mathrm{v} / \mathrm{v})$. The gradient program used as follows: $0 \mathrm{~min}, 10 \% \mathrm{~B}$; 0-27 min, $36 \% \mathrm{~B} ; 27-32 \mathrm{~min}, 60 \% \mathrm{~B} ; 32-35 \mathrm{~min}, 60 \% \mathrm{~B} ; 35-35.01$ $\min , 10 \% \mathrm{~B} ; 35.01-40 \mathrm{~min}, 10 \% \mathrm{~B}$. Orientin, isoorientin vitexin, isovitexin, rutin and quercetin $1 \mathrm{mg} / 10 \mathrm{~mL}$ was used as an external standard. Quantification of the different compounds was based on peak areas and calculated as equivalents of representative standard compounds. All contents were expressed as milligram per g dry weight (DW).

\section{RESULTS AND DISCUSSION}

Variations of volatile compounds in buckwheat sprouts: The volatile compounds from ten different buckwheat sprouts were extracted using solvent-free solid injector and detected using GC and GC/MS. The identified volatile compounds are showed in Table- 1 and Fig. 2. A total of 35 volatile compounds were tentatively detected and identified in one or more buckwheat sprouts. These compounds included amines and amine derivatives (5 compounds), alcohols and alcohol derivatives ( 7 compounds), aldehydes (3 compounds), anhydrides (3 compounds), acids (4 compounds), ketones and ketone derivatives ( 5 compounds), esters and ester derivatives ( 7 compounds) and carbon monoxide. Among the 35 compounds were identified: 8 compounds were notices in 'Dawon', 11 in 'Sewon', 17 in 'Yangieol', 9 in 'Yangieol', 16 in Commercial Asia, 11 in 'Daekwan', 6 in 'Kitawase', 8 in 'Hokkai-T9', 12 in 'Kokkai-T10' and 13 in Hwang-Hokkai-T10, respectively. Alcohol, ester and ketone containing compounds were the most numerous among all the compounds, whereas Jingke et al. ${ }^{10}$ reported that aldehydes and benzene-containing compounds were the most numerous in brown millet. The major volatile components present in Commercial Asia was N-(2-aminopropanoyl)leucine (13\%), 3,7,11,15-tetramethyl-2-hexadecen1-ol (11\%), 1-hexadecanol (19\%), 3-isobutylhexahydropyrrolo[1,2-a]pyrazine-1,4-dione (7.6\%), dibutyl phthalate $(15 \%)$ and ethyl iso-allocholate (13\%) respectively, whereas common buckwheat Kittawase contains carbon monoxide (40\%), 3,7,11,15-tetramethyl-2-hexadecen-1-ol (15\%), 1hexadecanol $(11 \%)$ and dibutyl phthalate $(19 \%)$, respectively.

Alcohols and ester derivatives represented the largest chemical groups among the different volatile components detected in all the buckwheat samples representing $20 \%$ each of the total volatile compounds. The contents of alcohols and ester derivatives were varied in all the ten samples by qualitatively and quantitatively. Among the alcohol group volatile compounds, 3, 7, 11, 15-tetramethyl-2-hexadecen-1-ol and 1-hexadecanol observed in all the samples however 1-hexadecanol was dominant (19.0\%) in Commercial Asia and $11 \%$ in 'Kitawase'. Degradation of the secondary hydroperoxides of unsaturated fatty acids leads to the formation of alcohols in plants ${ }^{17}$. Fruity and grassy natures of the cereals are mainly because of the presence of alcohols in the plants. The presence of 1-pentanol and 1-octanol compounds in paddy exhibited fruity and aromatic characteristics, respectively ${ }^{18,19}$. Esters derived compounds identified in the samples were 7,10-octadecadienoic acid, methyl ester, 9,12,15-octadecatrienoic acid, 2,3-dihydroxypropyl ester, (Z,Z,Z)- , 9-octadecenoic acid, (2-phenyl-1,3-dioxolan-4-yl)methyl ester, trans- etc. 7,10octadecadienoic acid and methyl ester were only present in 'Sewon' (1.63\%). Ester derived compounds in buckwheat have relatively high flavour thresholds and may lightly contribute to the odour like the esters in brown millets ${ }^{10}$.

The second largest compounds detected in buckwheat sprouts were ketone derivatives and amine derivatives (14.29\%). The compounds 1-hydroxy-2-propanone, 3,6diisobutyl-2,5-piperazinedione, 3-iso butyl hexa hydropyrrolo [1,2-a]pyrazine-1,4-dione, 3-iso pentylhexa hydropyrrolo [1,2a]pyrazine-1,4-dione and 2,5-piperazinedione, 3-benzyl-6-isopropyl- were unique ketones detected in 'Dawon', 'Sewon', 'Yangjeol', Commercial Asia, 'Dekwon 3-3', 'Kitawase', 'Hokkai $\mathrm{T} 10$ ' and Hwang-Hokkai T 10, respectively. The unsaturated fatty acids such as palmitoleic acid, oleic acid, myristoleic 


\begin{tabular}{|c|c|c|c|c|c|c|c|c|c|c|c|c|c|c|}
\hline \multirow{3}{*}{ No. } & \multicolumn{14}{|c|}{$\begin{array}{l}\text { TABLE-1 } \\
\text { RETENTION TIME (RT), RETENTION INDEX (RI) AND AREA PERCENTAGES OF THE VOLATILE } \\
\text { COMPOUNDS OF BUCKWHEAT SPROUT IDENTIFIED BY GC-MS }\end{array}$} \\
\hline & \multirow[t]{2}{*}{ Compound Name } & \multirow[t]{2}{*}{ RT } & \multirow[t]{2}{*}{ RI } & \multirow{2}{*}{ Blank — } & \multicolumn{10}{|c|}{ Area percentage (\%) } \\
\hline & & & & & 1 & 2 & 3 & 4 & 5 & 6 & 7 & 8 & 9 & 10 \\
\hline 1 & (2-Aziridinylethyl) amine & 1.392 & $<800$ & 59.7 & 6.12 & 35.8 & 28.5 & 12 & 1.8 & 50.0 & 0.9 & 30.0 & 8.9 & 5.2 \\
\hline 2 & Hydroxyacetic acid & 1.513 & $<800$ & & & & & 0.4 & & & & & & \\
\hline 3 & 2-Methylpropanal & 1.716 & $<800$ & & & & 2.31 & & 1.1 & & & & & \\
\hline 4 & 3-Methylbutanal & 2.154 & $<800$ & & & 2.82 & 4.91 & & 1.3 & 4.5 & & & 0.8 & 1.0 \\
\hline 5 & 2-Methylbutanal & 2.228 & $<800$ & & & & 4.26 & & & 2.3 & & & & \\
\hline 6 & Acetic formic anhydride & 2.523 & $<800$ & & & & & & & & & 2.9 & & 3.3 \\
\hline 7 & Acetic acid & 2.686 & $<800$ & & & & & & & & & & 5.7 & \\
\hline 8 & 1-Hydroxy-2-propanone/ Acetol & 3.073 & $<800$ & & & & & & 1.2 & & & & 2.7 & 2.7 \\
\hline 9 & 2,3-Butanediol, [R-( $\left.\left.\mathrm{R}^{*}, \mathrm{R}^{*}\right)\right]-/ 2,3$-Butanediol & 4.067 & $<800$ & & & & 7.42 & & & & & & 2.0 & \\
\hline 10 & Methylpyrazine & 4.747 & 863 & & & & & & & & & & & 3.6 \\
\hline 11 & Carbon monoxide & 8.574 & 939.69 & 32.4 & 29.6 & & 4.77 & & 3.4 & 3.3 & 40.0 & 3.5 & 4.5 & 11.0 \\
\hline 12 & dl-Alanyl-l-leucine/ N-(2-Aminopropanoyl)leucine & 36.53 & 1746.71 & & 9.92 & 10.6 & 7.11 & 16 & 13.0 & & & 17.0 & 17.0 & 14.0 \\
\hline 13 & 3,7,11,15-Tetramethyl-2-hexadecen-1-ol/Phytol & 39.03 & 1837.88 & & 6.85 & 10.3 & 5.4 & 16 & 11.0 & 8.2 & 15.0 & 6.6 & 11.1 & 8.3 \\
\hline 14 & 1-Hexadecanol & 40.15 & 1879.82 & 1.94 & 9.83 & 10.8 & 5 & 9.1 & 19.0 & 7.0 & 11.0 & 9.4 & 9.9 & 7.8 \\
\hline 15 & 3,6-Diisobutyl-2,5-piperazinedione & 41.58 & 1935.69 & & & & & & 4.8 & & & & & \\
\hline 16 & 3-Isobutylhexahydropyrrolo[1,2-a]pyrazine-1,4-dione & 41.65 & 1938.22 & & 4.48 & 3.45 & 0.93 & 6.7 & & & 6.5 & & 6.0 & 5.1 \\
\hline 17 & $\begin{array}{l}\text { 5,10-Diethoxy-2,3,7,8-tetrahydro-1H, } 6 \mathrm{H}^{-} \\
\text {dipyrrolo[1,2-a;1',2'-d]pyrazine }\end{array}$ & 41.71 & 1940.55 & & 1.71 & 2.08 & & 2.2 & & & & & 3.8 & 3.1 \\
\hline 18 & 3-Isopenylhexahydropyrrolo[1,2-a]pyrazine-1,4-dione & 41.89 & 1947.67 & & & & & & 7.6 & 3.3 & & & & \\
\hline 19 & 3,7,11-Trimethyl-1-dodecanol & 41.95 & 1950.16 & & & & & & & 3.4 & & & & \\
\hline 20 & Dibutyl phthalate & 42.32 & 1964.66 & 5.9 & 8.15 & 7.12 & 8.92 & 12 & 15.0 & 5.6 & 19.0 & 21.0 & 28.4 & 26.0 \\
\hline 21 & 9-Hexadecenoic acid & 45.23 & 2083.62 & & & & 4.23 & & & & & & & \\
\hline 22 & 7,10-Octadecadienoic acid, methyl ester & 45.56 & 2097.02 & & & 1.65 & & & & & & & & \\
\hline 23 & 9,12,15-Octadecatrienoic acid, 2,3 & 45.65 & 2100.78 & & & & & & 1.5 & & & & & \\
\hline 24 & $\begin{array}{l}\text {-dihydroxypropyl ester, (Z,Z,Z) } \\
\text { 9,12,15-Octadecatrienoic acid, methyl ester, (Z,Z,Z)- }\end{array}$ & 45.72 & 2103.89 & & & 2.22 & & & & & & & & \\
\hline 25 & 3-Hydroxydodecanoic acid & 45.96 & 2114.16 & & & & 1.52 & & & & & & & \\
\hline 26 & 9,12,15-Octadecatrienoic acid, ethyl ester, $(\mathrm{Z}, \mathrm{Z}, \mathrm{Z})$ - & 47.27 & 2170.73 & & & & & 4.9 & & 3.0 & & & & \\
\hline 27 & Deoxyspergualin & 47.59 & 2184.80 & & & & & & 2.5 & & & & & \\
\hline 28 & $\begin{array}{l}\text { 2,5-Piperazinedione, 3-benzyl-6-isopropyl-/ 3-Benzyl- } \\
\text { 6-isopropyl-2,5-piperazinedione }\end{array}$ & 48.73 & $>2200$ & & & & 2.74 & & & & & 3.5 & & \\
\hline 29 & 1,2-Dipalmitin & 50.09 & $>2200$ & & & & & & 2.4 & & & & & \\
\hline 30 & $\begin{array}{l}\text { 9-Octadecenoic acid, (2-phenyl-1,3-dioxolan- } \\
\text { 4-yl)methyl ester, trans- }\end{array}$ & 50.93 & $>2200$ & & & & 3.01 & & & & & & & \\
\hline 31 & $9,12,15$-Octadecatrienoic acid, 2,3 & 51.47 & $>2200$ & & & & 2.95 & & 2.1 & & & & & \\
\hline & -dihydroxypropyl ester, (Z,Z,Z)-/ à-Glyceryl linolenate & & & & & & & & & & & & & \\
\hline 32 & Oxiraneoctanoic acid, 3-octyl-, cis-/ Epoxyoleic acid & 51.48 & $>2200$ & & & & 2.15 & & & & & & & \\
\hline 33 & Ethyl iso-allocholate & 51.51 & $>2200$ & & & & & & 13.0 & & & & & 0.9 \\
\hline 34 & E,E,Z-1,3,12-Nonadecatriene-5,14-diol & 51.53 & $>2200$ & & & 0.88 & & & & & & & & \\
\hline 35 & $\begin{array}{l}\text { 9-Octadecenoic acid, (2-phenyl-1,3-dioxolan- } \\
\text { 4-yl)methyl ester, cis- }\end{array}$ & 53.93 & $>2200$ & & & & & & & 6.9 & & & & \\
\hline
\end{tabular}

acid, linoleic acid and arachidonic acid present in plants and vegetable upon oxidation leads to the generation of ketones ${ }^{17}$. Mixtures of ketones volatile compounds together provide the soapy and fruity characteristics of food, likewise these compounds may provide similar characteristics like other vegetables ${ }^{20}$.

Aldehydes and anhydrides represented the smallest group in the number of volatile components identified in all 10 buckwheats comprising $8.5 \%$ of the total volatile compounds detected. The volatile aldehyde fractions were mainly composed of 2-methylpropanal (detected in 'Yangjeol' [2.31\%] and Commercial Asia [1.1\%]), 3-methylbutanal (detected in 'Sewon' [2.82 \%], 'Yangjeol' [4.91\%], Commercial Asia [1.3\%], 'Daekwan 3-3' [4.5\%], 'Hokkai T 10' [0.8\%] and Hwang-Hokkai T 10 [1.0\%]). 2-Methylbutanal was unique in 'Yangjeol' (4.26\%) and 'Daekwan 3-3' (2.3\%) respectively. The compounds containing aldehydes as their functional groups are generally derived from the oxidation of the substrates such as unsaturated fatty acids by the action of specific enzymes present in cereals ${ }^{21-22}$. These enzymes mainly act on the carbon-carbon double bond of the unsaturated fatty acids. The aroma nature of the vegetables and cereals are mainly because of the presence of aldehydes containing compounds. The three aldehyde containing compounds detected in the three samples were belonged to the 2-alkenal and 3-alkadienal classes, respectively. (E,E)-2,4-nonadienal and (E,E)-2,4decadienal reported in rice was mainly contributed for the nutty and fatty characteristics ${ }^{19,20}$. Janeš et al. ${ }^{12}$ reported that salicylaldehyde, 2-phenylacetaldehyde, (E,E)-2,4-decadienal and (E)-2-nonenal in buckwheat mainly involved in the odor; whereas small amounts of aldehydes detected in the samples were mainly contribute for their odour.

Variation of phenolic compounds in buckwheat sprouts: The phenolic contents in the methanol extracts of different buckwheat sprouts were determined using HPLC and expressed $\mathrm{mg} / \mathrm{g}$ dry weight (Table-2). The results revealed that total phenolic content of common buckwheat $(50 \mathrm{mg} / \mathrm{g}$ dry weight) was comparatively higher than the other buckwheat species 




Fig. 2. Typical GC-MS chromatograms of volatile compounds extracted by SFSI from Buckwheat sprout (A) Blank, (B) Yong

\begin{tabular}{|c|c|c|c|c|c|c|c|}
\hline \multicolumn{8}{|c|}{$\begin{array}{c}\text { TABLE-2 } \\
\text { FLAVONOID CONTENTS }(\mathrm{mg} / \mathrm{G} \text { DRY WEIGHT) IN BUCKWHEAT SPROUT }(\mathrm{n}=3)\end{array}$} \\
\hline No. ${ }^{\text {(a) }}$ & Species & $\begin{array}{l}\text { Chlorogenic } \\
\text { acid }\end{array}$ & Orientin & Isoorientin Vitexin & Isovitexin & Rutin & Quercetir \\
\hline 1 & Dawon & $1.11 \pm 0.12$ & $9.14 \pm 0.55$ & $12.48 \pm 0.754 .57 \pm 0.16$ & $7.40 \pm 0.31$ & $5.92 \pm 0.41$ & $0.14 \pm 0.0140 .75 \pm 2.21$ \\
\hline 2 & Sewon & $1.30 \pm 0.10$ & $7.89 \pm 0.75$ & $10.80 \pm 1.014 .08 \pm 0.62$ & $6.72 \pm 0.62$ & $5.56 \pm 1.04$ & $0.15 \pm 0.0636 .55 \pm 3.87$ \\
\hline 3 & Yangjeol $^{(b)}$ & $0.09 \pm 0.00$ & $7.13 \pm 0.00$ & $10.04 \pm 0.003 .68 \pm 0.00$ & $6.35 \pm 0.00$ & $5.45 \pm 0.00$ & $0.12 \pm 0.00 \quad 32.86 \pm 0.00$ \\
\hline 4 & Yangjeol 2 & $1.34 \pm 0.17$ & $8.38 \pm 1.65$ & $11.71 \pm 2.543 .95 \pm 0.82$ & $6.43 \pm 1.57$ & $5.37 \pm 1.20$ & $0.14 \pm 0.02 \quad 37.33 \pm 7.57$ \\
\hline 5 & Asia & $1.23 \pm 0.07$ & $8.40 \pm 0.17$ & $11.50 \pm 0.22 \quad 4.67 \pm 0.09$ & $7.77 \pm 0.10$ & $5.50 \pm 0.04$ & $0.17 \pm 0.02 \quad 39.24 \pm 0.50$ \\
\hline 6 & Daekwan 3-3 & $32.81 \pm 0.25$ & $0.32 \pm 0.01$ & $0.40 \pm 0.02 \quad 0.98 \pm 0.03$ & $1.60 \pm 0.05$ & $34.40 \pm 0.77$ & $0.10 \pm 0.03 \quad 40.61 \pm 0.93$ \\
\hline 7 & Kitawase & $1.58 \pm 0.12$ & $11.16 \pm 0.36$ & $15.28 \pm 0.465 .47 \pm 0.08$ & $8.93 \pm 0.18$ & $7.36 \pm 0.21$ & $0.23 \pm 0.02 \quad 50.00 \pm 1.24$ \\
\hline 8 & Hokkai T 9 & $1.99 \pm 0.18$ & $0.29 \pm 0.03$ & $0.35 \pm 0.03 \quad 0.96 \pm 0.06$ & $1.47 \pm 0.10$ & $40.76 \pm 3.01$ & $0.23 \pm 0.06 \quad 45.96 \pm 3.29$ \\
\hline 9 & Hokkai T 10 & $2.70 \pm 0.31$ & $0.11 \pm 0.00$ & $0.18 \pm 0.01 \quad 1.11 \pm 0.19$ & $0.78 \pm 0.07$ & $38.27 \pm 3.87$ & $0.24 \pm 0.08 \quad 43.39 \pm 4.36$ \\
\hline 10 & $\begin{array}{l}\text { Hokkai T } \\
10 \text { (Hwang) }\end{array}$ & $2.85 \pm 0.04$ & $0.12 \pm 0.02$ & $0.20 \pm 0.01 \quad 1.23 \pm 0.11$ & $0.90 \pm 0.01$ & $40.58 \pm 1.35$ & $0.17 \pm 0.05 \quad 45.97 \pm 1.53$ \\
\hline
\end{tabular}


studied in the research. In other types of buckwheat, the content of total phenol was in the order: Hwang-Hokkai T 10 (45.97) $>$ 'Hokkai T 9' (45.96) > 'Hokkai T 10' (43.39) > 'Dawon' (40.75) > 'Daekwan 3-3' (40.61) > Commercial Asia (39.24) $>$ 'Yangjeol 2' (37.33) > 'Sewon' (36.55) > 'Yangjeol' (32.83 $\mathrm{mg} / \mathrm{g}$ dry weight) respectively.

The individual phenolic compounds such as rutin, vitexin, isovitexin, orientin, isoorientin, quercetin and chlorogenic acid in different buckwheat vegetables is shown in Table-2. The results showed that the amount of rutin was present in highest amount in 'Daekwan 3-3' and tartary buckwheat vegetables (34.40, 40.76, 38.27 and $40.58 \mathrm{mg} / \mathrm{g}$ dry weight, respectively). Besides rutin, four C-glycosylflavones such as orientin, isoorientin, vitexin and isovitexin were also higher in 'Kitawase' $(11.16,15.28,5.47$ and $8.93 \mathrm{mg} / \mathrm{g}$ dry weight) respectively. Similar trend was also observed in 'Yangjeol 2' and Commercial Asia buckwheat vegetables for orientin and isoorientin contents; however, their contents were 25 and $27 \%$ lower than in common buckwheat. Tartary buckwheat varieties such as 'Hokkai T 9', 'Hokkai T 10' and Hwang-Hokkai T 10 exhibited comparatively similar trend in C-glycosylflavones (orientin, isoorientin, vitexin and isovitexin), chlorogenic acid and rutin. Quercetin was quantified as extremely low level (less than 0. $1 \mathrm{mg} / \mathrm{g}$ dry weight) in all the evaluated buckwheat sprout. Chlorogenic acid contents were ranged 0.09-2.85 mg/g dry weight and they were higher in Hwang-Hokkai T 10 (2.85 \pm $0.04)$ and lower levels were observed in 'Yangjeol' $(0.09 \mathrm{mg} / \mathrm{g}$ dry weight). The functionality of buckwheat plants has been evaluated from the levels of rutin because of its anti-blood pressure effects (hypertention). Rutin was present in highest amounts (40.76) in 'Hokkai T 9' and Hwang-Hokkai T 1040.58 $\mathrm{mg} / \mathrm{g}$ dry weight respectively), whereas other buckwheats such as 'Dawon', 'Sewon', Commercial Asia, 'Yangjeol' and 'Kitawase' produced 8 fold (mean $5.86 \mathrm{mg} / \mathrm{g}$ dry weight) lesser than the tartary buckwheat concentration. This variation in the concentration of rutin among the different buckwheat could be due to the reasons such as genetic nature of buck wheat or the cultivation methods were the exposure to lights and also the age of the buckwheat sprouts affects the phenolic and flavonoids composition of buckwheat sprouts ${ }^{12,16-23}$.

\section{Conclusion}

The present study, variation of 35 volatile compounds and 7 phenolic compounds in 10 varieties of buckwheats were studied. Among the volatile compounds, functional groups containing alcohols and ester derivatives shared highest value among all of the volatile compounds determined (20\%). It is concluded that, all the varieties of buckwheat can be regarded as a potent source of phenolics (rutin, quercetin, vitexin, isovitexin, orientin isoorientin and chlorogenic acids) and has high antioxidant activities. Rutin represented about $95 \%$ of the total content of phenolics in 'Daekwan 3-3', 'Kitawase',
'Hokkai T 9', 'Hokkai T 10' and Hwang-Hokkai T 10 but produced only $15 \%$ in other varieties. Seed sprouts of buckwheats represent excellent nutritional sources of phenolic and volatile compounds and show potential antioxidant activities.

\section{ACKNOWLEDGEMENTS}

This study was financially supported by research fund of Chungnam National University in 2011. The author also thankful to Addiriyah Chair for Environmental Studies, Department of Botany and Microbiology, College of Science, King Saud University, Saudi Arabia for partial finance assistance.

\section{REFERENCES}

1. G. Mazza, T. Cottrell, L. Malcolmson, B. Girard, B.D. Oomah and M.A.M. Eskins, J. Food Qual., 22, 341 (1999).

2. S. Ikeda, T. Yamashita and T. Murakami, In Current Advances in Buckwheat Research Shinshu, Japan (1995).

3. G. Zhao, Y. Tang, R. Ma and Z. Hu. The Proceeding of the 8 "' ISB, p. 503 (2001).

4. I. Hinneburg and R.H.H. Neubert, J. Agric. Food Chem., 53, 3 (2005).

5. J. Kalinova, J. Triska and N. Vrchotova, J. Agric. Food Chem., 54, 5330 (2006).

6. K. Azuma, M. Nakayama, M. Koshioka, K. Ippoushi, Y. Yamaguchi, K. Kohata, Y. Yamauchi, H. Ito and H. Higashio, J. Agric. Food Chem., 47, 3963 (1999).

7. I. Hinneburg, S. Kempe, H.H. Ruttinger and R.H.H. Neubert, Pharmazie, 61, 237 (2006).

8. S.Q. Li and Q.H. Zhang. Crit. Rev. Food Sci. Nutr., 41, 451 (2001).

9. C. Aliaga and E.A. Lissi, Can. J. Chem., 82, 1668 (2004).

10. J.K. Liu, X. Tang, Y.Z. Zhang and W. Zhao, Molecules, 17, 2271 (2012).

11. H. Prosen, M. Kokalj, D. Janes and S. Kreft, Food Chem., 121, 298 (2010).

12. D. Janěs, D. Kantar, S. Kreft and H. Prosen, Food Chem., 112, 120 (2009).

13. D. Janes and S. Kreft, Food Chem., 109, 293 (2008).

14. S.-J. Kim, I.S.M. Zaidul, T. Maeda, T. Suzuki, N. Hashimoto, S. Takigawa, T. Noda, C. Matsuura-Endo and H. Yamauchi, Sci. Hortic., 115, 13 (2007).

15. S.-J. Kim, T. Maeda, Zaidul, S. Takigawa, C. Matsuura-Endo, H. Yamauchi, Y. Mukasa, K. Saito, N. Hashimoto, T. Noda, T. Saito and T. Suzuki, J. Agric. Food Chem., 55, 6314 (2007).

16. S.-J. Kim, I.S.M. Zaidul, T. Suzuki, Y. Mukasa, N. Hashimoto, S. Takigawa, T. Noda, C. Matsuura-Endo and H. Yamauchi, Food Chem., 110, 814 (2008).

17. W. Grosch, in eds.: I.D. Morton and A.J. Macleod, In Food Flavors. Part A. Introduction, edn 1, Elsevier: Amsterdam, The Netherlands, (1983).

18. J.S. Park, K.Y. Kim and H.H. Baek, Food Sci. Biotechnol., 19, 1403 (2010).

19. D.S. Yang, K.S. Lee, O.Y. Jeong, K.J. Kim and S.J. Kays, J. Agric. Food Chem., 56, 235 (2008).

20. D.S. Yang, R.L. Shewfelt, K.S. Lee and S.J. Kays, J. Agric. Food Chem., 56, 2780 (2008).

21. V. Varlet, C. Prost and T. Serot, Food Chem., 105, 1536 (2007).

22. R.G. Buttery, R. Teranishi, L.C. Ling and J.G. Turnbaugh, J. Agric. Food Chem, 38, 336 (1990).

23. S.J. Kim, C. Kawaharada, T. Suzuki, K. Saito, N. Hashimoto, S. Takigawa, T. Noda, C. Matsuura-Endo and H. Yamauchi, Food Sci. Technol. Res., 12, 199 (2006). 